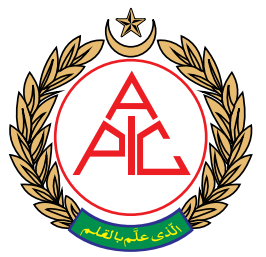

${ }^{1}$ Department of

Anesthesiology, the University of Texas Medical Branch at Galveston, Galveston, Texas, (USA)

${ }^{2}$ Department of

Anesthesiology, The University of Texas Medical Branch at Galveston, Galveston, Texas and Outcomes Research Consortium, Cleveland Clinic, Cleveland, Ohio, (USA)

Correspondence: Ejaz Khan, Fellow Obstetric Anesthesia, Department of

Anesthesiology,

The University of Texas

Medical Branch

301 University Blvd, Galveston Texas, 77555

Phone: 216-482-6696, E-mail: ejaz hzai@hotmail.com

Received: 31 December 2019

Reviewed: 15, 31 Jan 2020

Revised: 11 February 2020

Accepted: 25 March 2020

\section{Late onset postpartum eclampsia complicated with posterior reversible encephalopathy syndrome}

\author{
Ejaz Khan, $\mathrm{MD}^{1}$, Rovnat Babazade, $\mathrm{MD}^{2}$
}

\begin{abstract}
Posterior reversible encephalopathy syndrome (PRES) is a rare entity characterized by headache, vomiting, visual disturbances, seizure and unconsciousness with characteristic magnetic resonance imaging. Late onset postpartum eclampsia complicated by PRES has been reported in the literature,

We report a unique case of 23-year-old patient who developed late onset postpartum eclampsia complicated by PRES and acute kidney injury requiring renal replacement therapy. The case report emphasizes the need to continue antihypertensive medication in hypertensive parturients during postpartum period for at least 6 weeks as frequency of late postpartum eclampsia is high. The medication should be tapered off slowly to avoid reactive hypertensive episode which might trigger PRES and acute kidney injury.
\end{abstract}

Key words: Acute kidney injury; Late postpartum eclampsia; Posterior reversible encephalopathy syndrome; PRES; Renal replacement therapy

Citation: Khan E, Babazade R. Late onset postpartum eclampsia complicated with posterior reversible encephalopathy syndrome and acute kidney injury. Anaesth. pain intensive care 2019;23(2):234-236 DOI: https://doi.org/10.35975/apic.v24i1.1261

\section{INTRODUCTION}

Pre-eclampsia and eclampsia are systemic disorders of pregnancy and puerperium. Preeclampsia is defined by the presence of hypertension and proteinuria after 20th week's gestation. ${ }^{1}$ Eclampsia is the occurrence of seizure in a pregnant or recently delivered woman coupled with hypertension and proteinuria. Late postpartum eclampsia is the term used when a convulsion occurs more than $48 \mathrm{~h}$ after, but less than 4 weeks postpartum. ${ }^{1}$ Posterior reversible encephalopathy syndrome (PRES) is a clinical syndrome characterized by visual impairment, acute headaches, seizures and altered sensorium. ${ }^{2}$ Pre-eclampsia and eclampsia are the most common causes of PRES in obstetric patients. ${ }^{3}$ Pre-eclampsia is complicated by acute kidney injury (AKI) in about $1 \%$ of cases. ${ }^{4}$

We report a unique case of 23-year-old patient who developed late postpartum eclampsia complicated by PRES and acute kidney injury. To our knowledge this is the first case report in the literature. Written informed consent was obtained from the patient for publication of this case report and accompanying images. 


\section{CASE REPORT}

A 23-year-old lady, primigravida, had had cesarean section for severe pre-eclampsia. She was discharged and put on tab nifedipine and tab labetalol. Two weeks later her antihypertensive medications were tapered off amid repeated normal blood pressure (BP) readings in the morning. On the day of cessation of the therapy, her systolic BP shoot up in the evening up to $160-180 \mathrm{mmHg}$, and she had a tonic clonic seizure for about $2 \mathrm{~min}$ as witnessed and stated by her husband. The patient denied any past medical or surgical history except for severe pre-eclampsia.

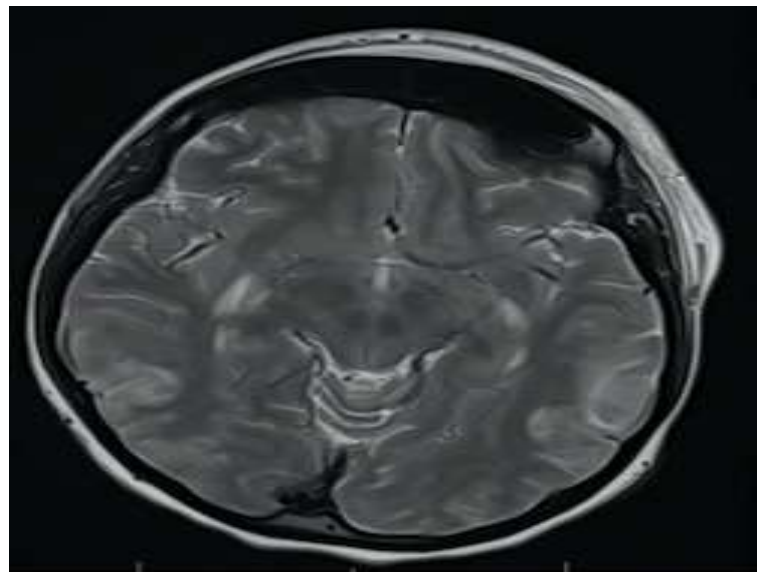

Figure 1: Increased T2-flair- signal in the bilateral posterior parietal, occipital, temporal lobes, deep gray nuclei and periventricular white matter

At the time of admission her vital signs were; $\mathrm{BP}$ at $180 / 100 \mathrm{mmHg}$ despite three doses of 10 mg hydralazine IV, heart rate 110/min and a respiratory rate $12 / \mathrm{min}$. Her physical exam was unremarkable, except for mild drowsiness. Patient received inj magnesium sulphate 4 g IV loading dose, followed by $2 \mathrm{~g} / \mathrm{h}$ infusion and became seizure free. She complained of frontal headache with blurred vision, hence a computed tomography scan (CT) was ordered, which revealed some evidence of cerebral venous sinus thrombosis. Magnetic resonance imaging (MRI) brain without contrast was then done, which showed increased T2 fluid attenuated inversion recovery (FLAIR) signal in the bilateral posterior parietal, occipital, and temporal lobes most likely representing PRES (Figure 1).

Patient was started with nicardipine drip for her resistant hypertension and was titrated and controlled by four different oral antihypertensive drugs over next $48 \mathrm{~h}$. Over a period of two days, patient's kidney functions deteriorated. Serum creatinine was $1.35 \mathrm{mg} / \mathrm{dl}$ on admission; it increased and plateaued at $5 \mathrm{mg} / \mathrm{dl}$ on 3rd admission day, after which hemodialysis had to be started. She underwent extensive work up for secondary hypertension but was unequivocal. She was tested for lupus nephritis, thrombotic thrombocytopenic

purpura, hemolytic uremic syndrome, antiphosp holipid syndrome and pheochromocytoma. A renal ultrasound was also performed. But all tests were negative.

Patient's blurred vision and headache resolved with BP control and her renal parameters improved with hemodialysis. Patient was discharged home with nephrology follow up as an outpatient. Patient remained on renal replacement therapy. Follow up brain MRI was done after two weeks, which revealed almost complete remission of signal abnormalities.

\section{DISCUSSION}

Late postpartum eclampsia accounts for $14 \%$ of eclampsia cases and is one of the known causes of PRES. PRES was first described by Hinchey et al. in $1996 .^{5}$ It is a reversible neurological syndrome characterized by the presence of white matter edema affecting mainly occipital and parietal lobes. The exact incidence of PRES is unknown. Most common triggers are acute hypertension, ${ }^{6}$ but patients may have other comorbid conditions that may predispose them to develop PRES.

The hallmark of PRES is the reversibility of symptoms with adequate control of $\mathrm{BP}$ and seizures in majority of the patients; however, permanent neurological sequelae or even death can occur in some patients. ${ }^{7} \quad$ Acute hypertensive episode due to reflex hypertension 
secondary to sudden stoppage of antihypertensive medication might have triggered both PRES and eclampsia in our patient. Late postpartum eclampsia complicated by PRES has been reported before, however, acute kidney injury in patient with PRES has not been reported in the literature.

Hypertensive complications of pregnancy are the leading cause of pregnancy related $\mathrm{AKI}^{8}{ }^{8}$ Although the incidence of severe AKI is low, outcome is poor. Interestingly, serum creatinine remained stable in our patient when BP were tightly controlled with nicardipine drip and were up trending once patient was off nicardipine, probably due to resistant hypertension. Our patient needed renal replacement therapy and her serum creatinine improved with few sessions of hemodialysis.

In conclusion continue antihypertensive medication in postpartum period till 6 weeks as occurrence of late postpartum eclampsia is high. BP medication should be titrated slowly to avoid reactive hypertensive episode which might triggered PRES and acute kidney injury.

Declaration of interests: None declared by the authors.

Funding: Study funded internally by Department of Anesthesiology, University of Texas Medical Branch

Authors' contribution: Both authors took equal part in management of the patient and preparation of this manuscript.

\section{REFERENCES}

1. Lubarsky SL, Barton JR, Friedman SA, Nasreddine S, Ramadan MK, Sibai BM. Late postpartum eclampsia revisited . Obstet Gynecol.1994 Apr;83(4):502-5. [PubMed] DOI: 10.1097/00006250-19940400000003

2. Roth $C$, Ferbert $A$. The posterior reversible encephalopathy syndrome: what's certain, what's new? Pract Neurol. 2011 Jun;11(3):136-44. [PubMed] DOI: 10.1136/practneurol-2011-000010

3. Zhang L, Wang Y, Shi L, Cao J, Li $Z$, Wáng $\quad Y X$. Late postpartum eclampsia complic ated with posterior reversible encephalopathy syndrome: a case report and a literature review. Quant
Imaging Med Surg. 2015 Dec;5(6):909-16. [PubMed] DOI: 10.3978/j.issn.22234292.2015 .12 .04

4. Kuklina EV, Ayala C, Callaghan WM. Hypertensive disorders and severe obstetric morbidity in the United States. Obstet Gynecol. 2009 Jun;113(6):1299-306. [PubMed] DOl: 10.1097/AOG.0b013e3181a45b25

5. Hinchey J, Chaves C, Appignani B, Breen J, Pao L, Wang A, et al. A reversible posterior leukoencephalopathy syndrome. N Engl J Med. 1996 Feb 22;334(8):494-500. [PubMed] DOI: 10.1056/NEJM199602223340803

6. Roth C, Ferbert A. athy syndrome: what's certain, what' s new? Pract Neurol. 2011 Jun;11(3):136-44. [PubMed] DOI: 10.1136/practneurol-2011-000010

7. Covarrubias DJ, Luetmer $\mathrm{PH}$, Campeau NG. Posterior reversible encephalopathy syndrome: prognostic utility of quantitative diffusion-weighted MR images. AJNR Am J Neuroradiol. 2002 Jun-Jul;23(6):1038-48. [PubMed]

8. Arora N, Mahajan $\mathrm{K}$, Jana N, Taraphder A. Pregnancyrelated acute renal failure in eastern India. Int J Gynaecol Obstet. 2010 Dec;111(3):213-6. [PubMed] DOI: $\underline{10.1016 / \text { i.jigo.2010.06.026 }}$ 